\title{
Ensino de eletricidade via bancada luminotécnica e simulador PhET
}

Rafael Costa Araújo ${ }^{1}$, Moisés Abreu de Sousa ${ }^{1}$, Rodrigo Rangel Ribeiro Bezerra', Glaura Caroena Azevedo de Oliveira ${ }^{1}$, Fernanda Carla Lima Ferreira ${ }^{1}$, Divanizia Nascimento de Souza ${ }^{2}$, Andréa de Lima Ferreira Novais $^{1}$

${ }^{1}$ Universidade Federal do Sul e Sudeste do Pará (UNIFESSPA)

${ }^{2}$ Universidade Federal de Sergipe (UFS)

Palavras-chave: Eletricidade, ensino de física, bancada luminotécnica.

\section{Introdução}

O ensino dos conceitos que envolvem os fenômenos elétricos no ensino médio se resume, na maioria das vezes, na apresentação dos conteúdos pelo professor e/ou resolução de exercícios. Neste contexto, uma proposta de ensino que incentive a utilização de atividades experimentais em consonância com atividades computacionais é necessária. A implementação dessa proposta leva a alguns questionamentos a respeito das vantagens e desvantagens no aprendizado dos estudantes quando comparadas com as aulas expositivas tradicionais (Santos \& Dickman, 2019).

Segundo Baquero (2001) as atividades experimentais são importantes para o desenvolvimento dos conceitos científicos. Já Fiolhais e Trindade (2003, p. 264), afirmam que "embora as simulações não devam substituir por completo a realidade que representam, elas são bastante úteis para abordar experiências difíceis ou impossíveis de serem realizadas na prática".

O presente trabalho apresenta uma proposta de pesquisa que visa comparar a utilização de experimentos concretos (bancada luminotécnica) e virtuais (simulador PhET Interactive Simulations) com as aulas tradicionais expositivas. Além de realizar um estudo comparativo entre o uso de experimentos concretos e virtuais no ensino de física (Santos; Dickman, 2019).

\section{Metodologia e material}

Para aplicar as atividades relacionadas aos experimentos concretos e virtuais serão escolhidas quatro turmas do ensino médio, duas do Colégio Equipe na cidade de Canaã dos Carajás-Pa e duas do Colégio Universo na cidade de Marabá-Pa. Inicialmente, será aplicado um questionário prévio contendo dez questões abertas relacionadas aos conceitos de eletricidade como: 'corrente elétrica, ${ }^{1}$ resistência elétrica e 'potência elétrica etc. Em seguida, os estudantes terão duas aulas teóricas (expositivas) sobre os conceitos abordados no questionário e farão cálculos de corrente elétrica, resistência elétrica e potência elétrica. O próximo passo será a apresentação da bancada luminotécnica contendo lâmpadas com diferentes potências e tensões, além de um amperímetro, como pode ser observado no modelo da Figura 1. Por fim, será realizada uma aula experimental, utilizando a bancada luminotécnica, onde a turma será dividida em grupos com até quatro estudantes com o mediador (professor) confrontando alguns conceitos relacionados a eletricidade, os grupos deverão realizar medidas de corrente, resistência etc. Ao final da aula experimental os grupos irão realizar cálculos teóricos de corrente e resistência etc., e comparar com os valores encontrados experimentalmente ${ }^{1}$.

\footnotetext{
${ }^{1}$ A expressão, $i=\frac{\Delta Q}{\Delta t}$ é a corrente elétrica estimada a partir da quantidade de carga que atravessa uma seção transversal do fio em um intervalo de tempo. As equações $R=\frac{V}{i}$ e $\mathrm{R}=\frac{\rho l}{A}$ tem relação com a resistência para qualquer condutor, se $R$ for constante essa relação é chamada de lei de Ohm. A expressão da potência dissipada por um resistor é $P=R i^{2}$ depende do valor da resistência do dispositivo e da corrente elétrica que passa por ele. A potência dissipada também pode ser representada por, $P=\frac{V^{2}}{R}$ ou por $P=V i$. Os parâmetros $V$ é a tensão, $A$ é a área e $\rho$ é a resistividade e $l$ é o comprimento do fio.
} 
Figura 1 - Modelo da bancada luminotécnica.

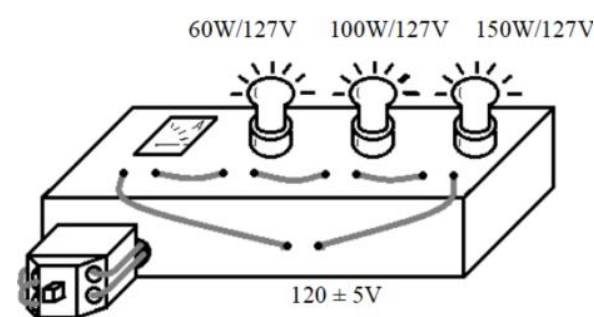

Fonte: Retirada de Laviola \& Marins, 2011.

Posteriormente, o software PhET Interactive Simulations que é um simulador que oferece simulações de matemática e ciências da terra, interativas, online e grátis, baseadas em pesquisas, como mostrado na Figura 2 será apresentado aos estudantes e os fenômenos observados na bancada luminotécnica serão simulados.

Figura 2 - Interface do simulador PhET.

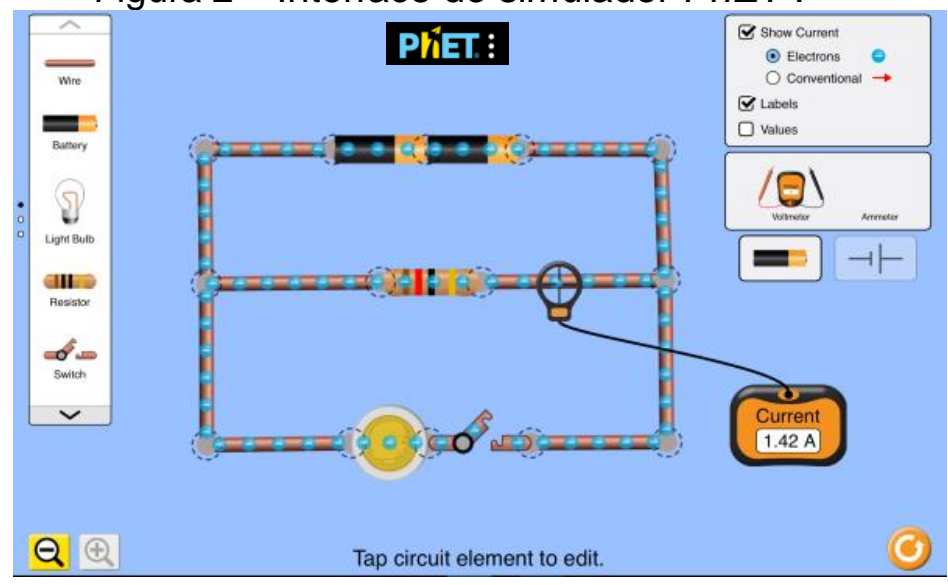

Fonte: Retirada de PhET Interactive Simulations.

Para a realização do diagnóstico a respeito das vantagens e/ou desvantagens de utilizar uma bancada luminotécnica e um simulador $P h E T$, será aplicado um questionário quali-quantitativo após a apresentação das ferramentas (bancada e simulador).

\section{Resultados esperados}

Espera-se que as vantagens e desvantagens de utilizar experimentos concretos e virtuais em relação a aulas tradicionais expositivas como ferramentas facilitadoras no processo ensino aprendizagem de física possam ser discutidas e apresentadas.

\section{Agradecimentos}

Os autores agradecem a Coordenação de Aperfeiçoamento de Pessoal de Nível Superior (CAPES), ao Mestrado Nacional Profissional em Ensino de Física (MNPEF) e a Universidade Federal do Sul e Sudeste do Pará (UNIFESSPA).

\section{Referências}

BAQUERO, R. Os Processos de Desenvolvimento e as Práticas Educativas. Trad.: ROSA, E. F. F. Vygotsky e a aprendizagem escolar. Porto Alegre: Artes Médicas, p.89, 2001.

FIOLHAIS, C.; TRINDADE, J. Rev. Bras. Ens. Fís. 25, 3, 2003.

LAVIOLA, M. S.; MARINS, L. A. Montagens de Circuitos Elétricos em Sala de Aula: Uma Contribuição Significativa no Processo Ensino-Aprendizagem. In: IV Encontro Estadual de Ensino de Física, IV, 2011, Porto Alegre.

SANTOS, J. C.; DICKMAN, A. G. Experimentos reais e virtuais: proposta para o ensino de eletricidade no nível médio. Revista Brasileira de Ensino de Física, vol. 41, no 1, 2019.

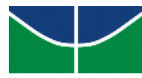

